\title{
Acute Antihypertensive Effects of Calcium Channel Blockers Are not Affected by Calcium Supplementation in Patients with Essential Hypertension
}

\author{
Koichi SATo, MD, Yasuaki DoHI, MD, \\ Koichi Miyagawa, MD, \\ and Masayoshi KoJIMA, MD
}

\begin{abstract}
SUMMARY
The study was designed to investigate whether the acute antihypertensive effects of calcium channel blockers are affected by calcium supplementation in patients with essential hypertension. The antihypertensive effects of calcium channel blockers (oral manidipine or intravenous nicardipine) were studied before and during calcium supplementation $(1200 \mathrm{mg} /$ day for 8 weeks) in 30 hospitalized patients with essential hypertension. The averages of systolic and diastolic blood pressure during a 24-hour period were not decreased by calcium supplementation. The acute antihypertensive effects of the calcium channel blockers nicardipine $(0.25,0.5,1.5,2.0 \mu \mathrm{g} / \mathrm{kg} / \mathrm{min}$, intravenous infusion) or manidipine ( $20 \mathrm{mg}$, once a day, orally) were not enhanced by calcium supplementation. Thus, calcium channel blockers can be safely combined with calcium supplementation in terms of blood pressure. (Jpn Heart J 1998; 39: 347353)
\end{abstract}

Key words: Blood pressure, Calcium supplementation, Calcium channel blocker, Essential hypertension, Treatment

$I^{N}$ Japan, many people usually have taken calcium for prophylaxis of osteoporosis and many hypertensive patients have taken calcium channel blocker as a main antihypertensive treatment. ${ }^{1,2)}$ Many people with hypertension take a calcium channel blocker in combination with calcium supplementation. Investigators in our division have previously demonstrated that the infusion of calcium increases total peripheral resistance and blood pressure by inhibiting the infusion of calcium channel blocker. ${ }^{3,4)}$ However, there are no reports of the acute antihypertensive effects of calcium channel blockers on the long-term treatment of calcium supplementation. It is necessary to investigate whether the acute antihypertensive effects of calcium channel blockers are affected by calcium

From the Division of Hypertension and Vascular Research, Second Department of Internal Medicine, Nagoya City University Hospital, Nagoya, Japan.

Address for correspondence: Koichi Sato, MD, Division of Hypertension and Vascular Research, Second Department of Internal Medicine, Nagoya City University Hospital, Mizuho-ku, Nagoya 467, Japan.

Received for publication December 9, 1997.

Accepted March 2, 1998. 
supplementation in patients with essential hypertension.

\section{Methods}

Subjects: Thirty patients with essential hypertension (16 males and $14 \mathrm{fe}$ males), 30 to 64 years of age, participated in the study (Table I). All had been treated for essential hypertension for at least 5 years and had mean diastolic blood pressure $>95 \mathrm{mmHg}$ and mean systolic blood pressure $>160 \mathrm{mmHg}$ before the medication. All medication, including antihypertensive drugs, were discontinued for at least 4 weeks before the study.

Procedure: Effects of calcium supplementation on antihypertensive effects induced by (1) oral manidipine or (2) intravenous nicardipine were studied.

All patients were admitted to our hospital and placed on a diet containing $\mathrm{NaCl} 8 \mathrm{~g} /$ day and calcium $600 \mathrm{mg} /$ day. Ambulatory blood pressure (ABPM90207, Nihon Kohden Ltd., Tokyo, Japan) (every hour for 24 hours) was measured twice at 3-day intervals; on the day of the second measurement, manidipine $(20 \mathrm{mg}$ ) was administered orally at $8 \mathrm{AM}$. Three days later, the effects of intravenous nicardipine were evaluated by direct measurement of arterial pressure. The patients were allowed to rest in a supine position into a quiet, comfortable room $\left(22-25^{\circ} \mathrm{C}\right)$ and a polyethylene catheter was introduced in the left radial artery under local anesthesia to monitor arterial blood pressure with a

Table I. Characteristics of 30 Hypertensive Subjects

\begin{tabular}{|c|c|}
\hline Age (years) & $50 \pm 9$ \\
\hline Body height $(\mathrm{cm})$ & $158 \pm 6$ \\
\hline Body weight, $(\mathrm{kg})$ & $57 \pm 5$ \\
\hline $\mathrm{SBP}(\mathrm{mmHg})$ & $178 \pm 10$ \\
\hline $\mathrm{DBP}(\mathrm{mmHg})$ & $107 \pm 5$ \\
\hline Heart rate (beats/min) & $72 \pm 9$ \\
\hline Fundus oculi & $\begin{array}{l}\mathrm{H} 1: 18, \mathrm{H} 2: 12 \\
\mathrm{~S} 0: 13, \mathrm{~S} 1: 10, \mathrm{~S} 2: 7\end{array}$ \\
\hline CTR $(\%)$ & $51 \pm 2$ \\
\hline $\mathrm{RV}_{5},(\mathrm{mV})$ & $2.5 \pm 0.7$ \\
\hline $\mathrm{RV}_{5}+\mathrm{SV}_{1}(\mathrm{mV})$ & $4.1 \pm 1.0$ \\
\hline ST, T change $(t /-)$ & $11 / 19$ \\
\hline \multicolumn{2}{|l|}{ Urinalysis } \\
\hline proteinuria, $(+/-)$ & $0 / 30$ \\
\hline glucosuria, $(+/-)$ & $0 / 30$ \\
\hline $\mathrm{BUN}(\mathrm{mg} / \mathrm{d} l)$ & $14 \pm 1$ \\
\hline $\mathrm{Cr}(\mathrm{mg} / \mathrm{d} l)$ & $0.7 \pm 0.2$ \\
\hline $\mathrm{Ca}(\mathrm{mg} / \mathrm{d} l)$ & $9.5 \pm 0.3$ \\
\hline $\mathrm{PTH}(\mathrm{ng} / \mathrm{m} l)$ & $0.34 \pm 0.07$ \\
\hline $\mathrm{PRA}(\mathrm{ng} / \mathrm{m} / / \mathrm{hr})$ & $1.9 \pm 0.4$ \\
\hline
\end{tabular}

$\mathrm{SBP}=$ systolic blood pressure; DBP = diastolic blood pressure; $\mathrm{CTR}=$ cardio-thoracic ratio; $\mathrm{BUN}=$ blood urine nitrogen; $\mathrm{Cr}=$ creatinine; $\mathrm{PTH}=$ parathyroid hormone; PRA = plasma renin activity. 
polygraph system (AP641G, Nihon Kohden Ltd.). Blood pressure was continuously recorded with a thermal array recorder. Heart rate was measured using a continuously monitored electrocardiogram. Increasing doses of nicardipine $(0.25$, $0.5,1.0,2.0 \mu \mathrm{g} / \mathrm{kg} / \mathrm{min}$ for $10 \mathrm{~min}$, respectively) diluted with $5 \%$ glucose solution $(0.2 \mathrm{mg} / \mathrm{m})$ were infused through the right antecubital vein with an infusion pump (model 2620; Harvard Apparatus, South Natick, MA, USA). Three days later, the antihypertensive effects of intravenous hydralazine $(10 \mathrm{mg}$ for $40 \mathrm{~min}$, $\mathrm{l} \mathrm{mg} / \mathrm{m}$ ) were studied.

The same procedures were performed 8 weeks after calcium supplementation (1200 mg elemental calcium in the form of a calcium carbonate) was started.

Manidipine was used because it is long-lasting and possesses highly selective vascular action with an extremely weak cardiodepressant action. Nicardipine was chosen for intravenous infusion since both manidipine and nicardipine are 1,4 dihydropyridine derivatives.

Drugs: Commercially available racemic solutions of nicardipine hydrochloride (Yamanouchi Pharmaceutical Co. Ltd., Tokyo), hydralazine hydrochloride (Ciba-Geigy, Takarazuka, Japan), manidipine hydrochloride (Takeda Pharmaceutical Co. Ltd., Tokyo), and calcium carbonate (Kenei Co. Ltd., Osaka, Japan) were used.

Ethics: The objectives and methods of the study were explained in detail to the patients and informed consent was obtained before the start of the study. The protocol was approved by the Ethics Committee of Nagoya City University Hospital.

Statistics: Values are expressed as mean (SD). Statistical comparisons were made by Student's paired $t$-test and the Bonferroni method when analysis of variance for repeated measurements demonstrated significant differences. Statistical significance was assumed when $p<0.05$.

\section{Results}

24-hour blood pressure: Calcium supplementation (1200 mg/day, 8 weeks) did not alter mean systolic or mean diastolic blood pressure, or mean heart rate (Figure 1, Table II). Manidipine decreased the mean of 24-hour blood pressure and increased that of heart rate before and during calcium supplementation (Figure 1, Table II). Neither the decrease in systolic or diastolic blood pressure nor the increase in heart rate were affected by calcium supplementation (Table II).

Intravenous nicardipine and hydralazine: Nicardipine $(0.25,0.5,1.0$ or 2.0 $\mu \mathrm{g} / \mathrm{kg} / \mathrm{min}$ for $10 \mathrm{~min}$ ) decreased blood pressure and increased heart rate dosedependently before and during calcium supplementation (Figure 2). The decrease 

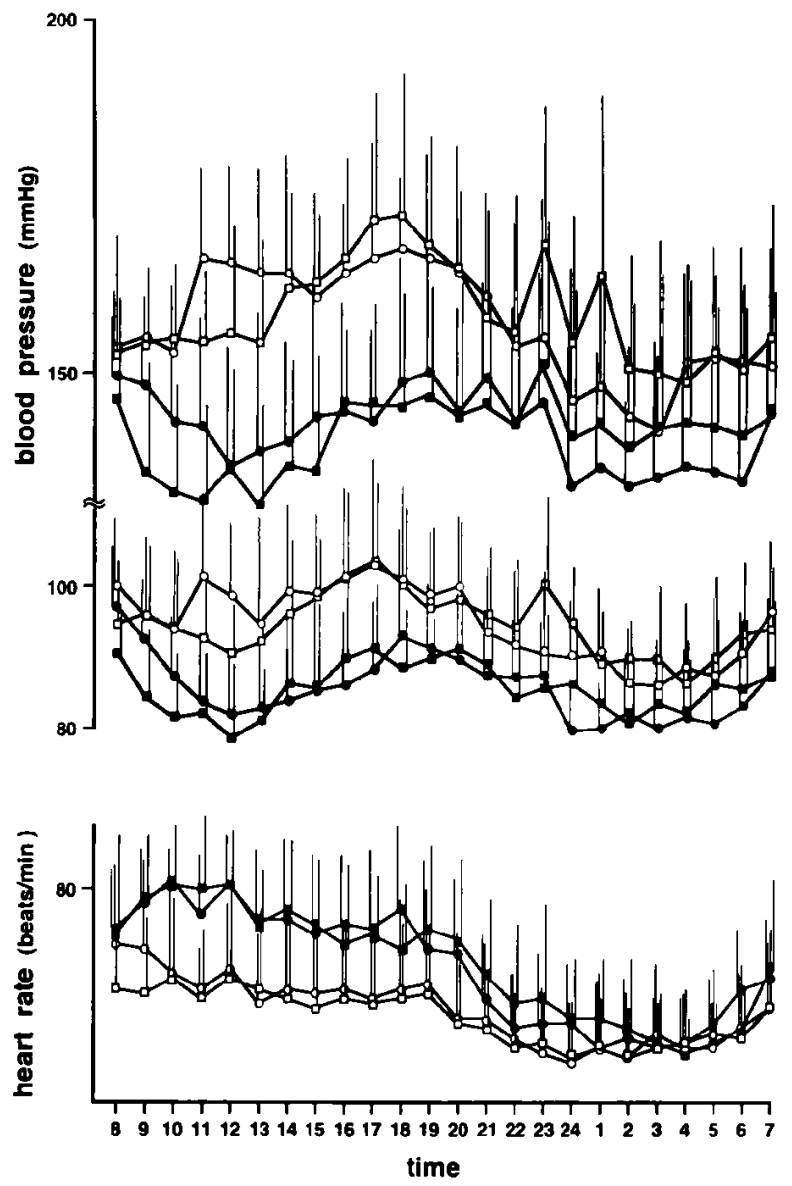

Figure 1. Line graphs showing effects of manidipine $(20 \mathrm{mg})$ on 24-hour blood pressure and heart rate before and during calcium supplementation $(1,200 \mathrm{mg}) . \mathrm{O}$ : control, manidipine $20 \mathrm{mg}, \square$ : calcium supplementation, $\square$ : manidipine $20 \mathrm{mg}$ with calcium supplementation. Arrow indicates the administration of manidipine. Values are mean $\pm \mathrm{SD}$.

Table II. Comparison of Averages in Blood Pressure and Heart Rate Measured for 24 Hours before and after Treatment with Manidipine and/or Calcium Supplementation

\begin{tabular}{lrrrrr}
\hline & \multicolumn{2}{c}{ Control } & & \multicolumn{2}{c}{ Calcium supplementation period } \\
\cline { 2 - 3 } \cline { 6 - 6 } & Baseline & Manidipine & & Baseline & Manidipine \\
\hline 24-hr SBP (mmHg) & $150 \pm 34$ & $135 \pm 31^{* *}$ & & $151 \pm 35$ & $135 \pm 31^{* *}$ \\
$24-\mathrm{hr} \mathrm{DBP}(\mathrm{mmHg})$ & $91 \pm 21$ & $82 \pm 19^{* *}$ & & $91 \pm 20$ & $82 \pm 18^{* *}$ \\
$24-\mathrm{hr} \mathrm{HR}(\mathrm{bpm})$ & $61 \pm 15$ & $66 \pm 17^{* *}$ & & $59 \pm 15$ & $67 \pm 17^{*}$ \\
\hline
\end{tabular}

Data are mean \pm SD. ${ }^{*} p<0.01,{ }^{* *} p<0.001$ vs. respective baseline values. $\mathrm{SBP}=$ systolic blood pressure; $\mathrm{DBP}=$ diastolic blood pressure; $\mathrm{HR}=$ heart rate. 

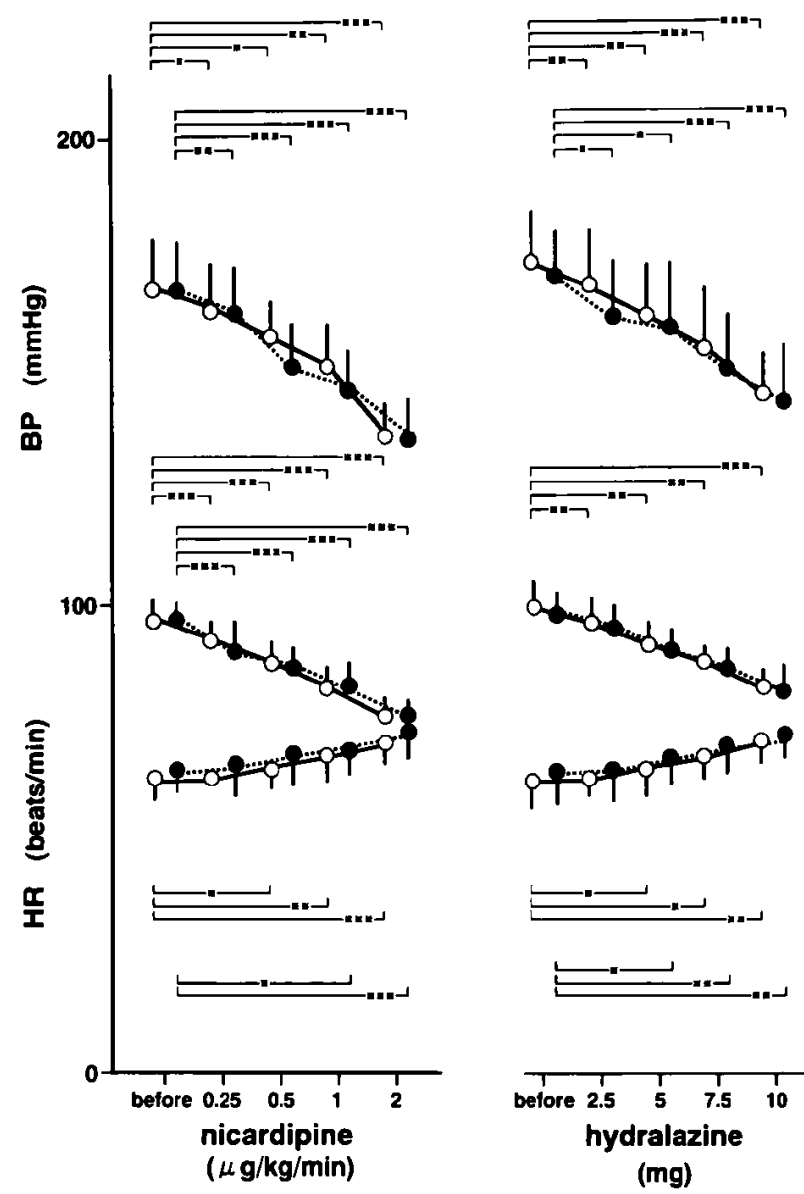

Figure 2. Line graphs showing effects of nicardipine (left) and hydralazine (right) on blood pressure and heart rate before $(\mathrm{O})$ and during calcium supplementation Values are mean $\pm \mathrm{SD} .{ }^{*} p<0.05,{ }^{* *} p<0.01,{ }^{* * *} p<0.001$ vs. values obtained before the infusion.

in blood pressure or the increase in heart rate were not affected by calcium supplementation. Similar results were obtained using hydralazine (Figure 2).

\section{Discussion}

Galcium supplementation did not decrease blood pressure in this study. In most epidemiologic studies, low dietary calcium intake is associated with an increased prevalence of hypertension. ${ }^{5-7)}$ Previously some studies shown that an increased calcium intakc lowers blood pressure. ${ }^{8)}$ However, the overall effect of an increased calcium intake is minimal. ${ }^{9,10)}$ Our results confirm the ncgative re- 
ports. We used $1200 \mathrm{mg}$ of elemental calcium in the form of calcium carbonate for 8 weeks as calcium supplementation. McCarron and Morris demonstrated that $1000 \mathrm{mg} /$ day of oral calcium for 8 weeks represents a safe and well-tolerated, and non-pharmacologic intervention. ${ }^{8)}$ Thus, the dose, form and duration of calcium supplementation must be adequate for evaluation of the effects of calcium supplementation.

The present study demonstrates that the acute antihypertensive effects of calcium channel blockers are not enhanced by calcium supplementation in patients with essential hypertension. An additive effect of calcium intake during pharmacological treatment with calcium channel blockers has been reported in SHR. " Although the reason for the discrepancy between the results obtained in the present clinical study and this previous experimental study is not certain, there are some possible explanations. First, an increase in extracellular calcium due to the increased calcium intake may have attenuated the action of calcium channel blockers which inhibit calcium influx through voltage-sensitive calcium channels. However, this is not likely since the other vasodilator, hydralazine, decreased during calcium supplementation the blood pressure to the same extent as did the calcium channel blocker, nicardipine. Second, we investigated the acute, but not the long-term, antihypertensive effects of the calcium channel blockers. It is possible that calcium supplementation enhances the effects of longterm treatment with calcium channel blockers. Indeed, in the previous study using SHR, nifedipine or verapamil was administered for 8 weeks. ${ }^{11}$ Third, high doses of calcium (1-4 g/day) and calcium channel blockers (two- to five-fold) might have an additive effect. ${ }^{11)}$ Fourth, in patients whose blood pressure decreases in response to calcium supplementation, this combination may evoke a synergistic effect. In our patients, calcium supplementation failed to reduce the blood pressure.

There were no adverse effects on hemodynamics induced by calcium channel blockers in the long-term treatment with calcium supplementation. Thus, it is safe to use the combination.

In conclusion, calcium supplementation had no effect on the acute antihypertensive effects of calcium channel blockers.

\section{REFERENCES}

1. DeSouza AC, Nakamura T, Stergiopoulos K, Shiraki M, Ouchi Y, Orimo H. Calcium requirement in elderly Japanese women. Gerontology 1991; 37 (Suppl 1): 43-7.

2. Takagawa $Y$, Shimamoto K. Masuda A, limura O. Survey of current drug therapy for elderly hypertension. Therapeutic Res 1995; 16: 3822-6.

3. Suzuki T, Aoki K. Hypertensive effects of calcium infusion in subjects with normotension and hypertension. J Hypertens 1988; 6: 1003-8.

4. Aoki K, Miyagawa K. Correlation of increased serum calcium with elevated blood pressure and 
vascular resistance during calcium infusion in normotensive man. J Hypertens 1990; 8: 57983.

5. McCarron DA. Calcium, magnesium, and phosphorus balance in human and experimental hypertension. Hypertension 1982; 4 (Suppl 3): 27-33.

6. Witteman JCM, Willett WC, Stampfer MJ, et al. A prospective study of nutritional factors and hypertension among US women. Circulation 1989; 80: 1320-7.

7. Cappuccio FP, Elliot P, Allender PS, Pryer J, Follman DA, Cutler JA. Epidemiologic association between dietary calcium intake and blood pressure: a meta-analysis of published data. Am J Epidemiol 1995; 142: 935-45.

8. McCarron DA, Morris CD. Blood pressure response to oral calcium in persons with mild to moderate hypertension. Ann Intern Med 1985; 103: 825-31.

9. Allender PS, Cutler JA, Follmann D, Cappuccio FP, Pryer J, Elliott P. Dietary calcium and blood pressure: a meta-analysis of randomized clinical trials. Ann Intern Med 1996; 124: 825-31.

10. The Sixth Report of Joint National Committee on Prevention, Detection, Evaluation, and Treatment of High Blood Pressure. NIH publication 1997; No. 98-4080: 22.

11. Pang PT, Benishin CG, Lewanczuk RZ. Combined effect of dietary calcium and calcium antagonists on blood pressure reduction in spontaneously hypertensive rats. J Cardiovasc Pharmacol 1992; 19: 4426. 